\title{
On the Essential Nature of Hematopoietic Function of Bone Marrow
}

\author{
Report 3 : On the Field of the Blood Defense Reaction
}

By

\author{
Akira Saito \\ From the Medical Department of Prof. S. Y a magata, Tohoku University \\ School of Medicine, Sendai
}

(Received for publication, March 14, 1961)

\begin{abstract}
PREFACE
The author has found that the principle of hematopoiesis in the bone marrow consists in the monophasic formation in the erythropoietic system, and in the diphasic formation in the leucopoietic system. Here the blood reactions must be duly apprehended in order to apprehend this principle duly.

From Pithecanthropus downward, the human body has been evolving and changing in an incessant struggle against microbes, during the fifty myriad years of the course of evolution. leucopoietic reaction in leucocytosis and leucopenia is one of a living creature's reactions obtained by an adaptation to the environment. Therefore, the observation of the blood reaction in the infectious diseases is the most rational way to study the principle of hematopoiesis in the bone marrow.
\end{abstract}

\section{Reaction Fields of Blood Cells and Serum Observed from the Angle of Internal Environment}

In infectious diseases, leucocytosis can be easily understood from the function of the white blood cells in the defense mechanism of the body, but leucopenia is seemingly inconsistent with this notion, for the decrease of the white blood cells means the decline of defense force against pathogenetic microbes.

This problem must be inquired from the point of bacterio-immunology, apart from the point of hematology.

In infectious diseases, there are differences between coccal infection and bacillary infection; increase of the white blood cells is larger in coccal infection than in bacillary infection, while on the contrary the production of antibodies in the serum is higher in the latter than in the former. In general, production of antibodies is active in the diseases involving leucopenia. Now the blood reactions 
partaking in the defense mechanism of the body is divided into the leucocytebacterium reaction and the serum-bacterium (antibody-antigen) reaction.

The followings are the experimental results obtained in the entire course of typhoid fever. In 536 typhoid fever cases during the term from entering to leaving hospital, the author cultivated typhoid bacilli 1727 times sampled from the bone marrow, blood, stool, urine and pharyngeal mucus at the rate of once a week regularly. Picking out $3 \mathrm{cc}$ of bone marrow specimen by bone-marrow puncture, putting it into 5-7 ce of bile media, and after enrichment for 24 hours therein it was painted on the surface of the Endo's media and cultivated at $37^{\circ} \mathrm{C}$. This procedure was repeated every day until the pathogenetic microbes were isolated as colonies, and when the cultures turned out to be negative after 5 day's enrichment in bile media I determined them to be negative. And at the same time, Widal's reaction of serum and peripheral blood was also examined. Fig. 1. presents the relation between the development of the bacilli in the bone marrow and the titers of Widal's reaction, obtained by these systematic serial examinations. The percentage of positive finding of the pathogenetic microbes is much higher in the bone marrow than in the blood, and is the highest at the early stage of the illness; in the first week of the illness, the percentage of positive findings was $91.9 \%$ in the bone marrow and $76.6 \%$ in the blood. Then the percentage gradually abated during its courses, but the curve of positive findings of the bacilli in the bone marrow dropped more slowly than in the blood. On the contrary, the Widal reaction presented nothing characteristic at the onset of the illness, but become positive during the second week and reached its

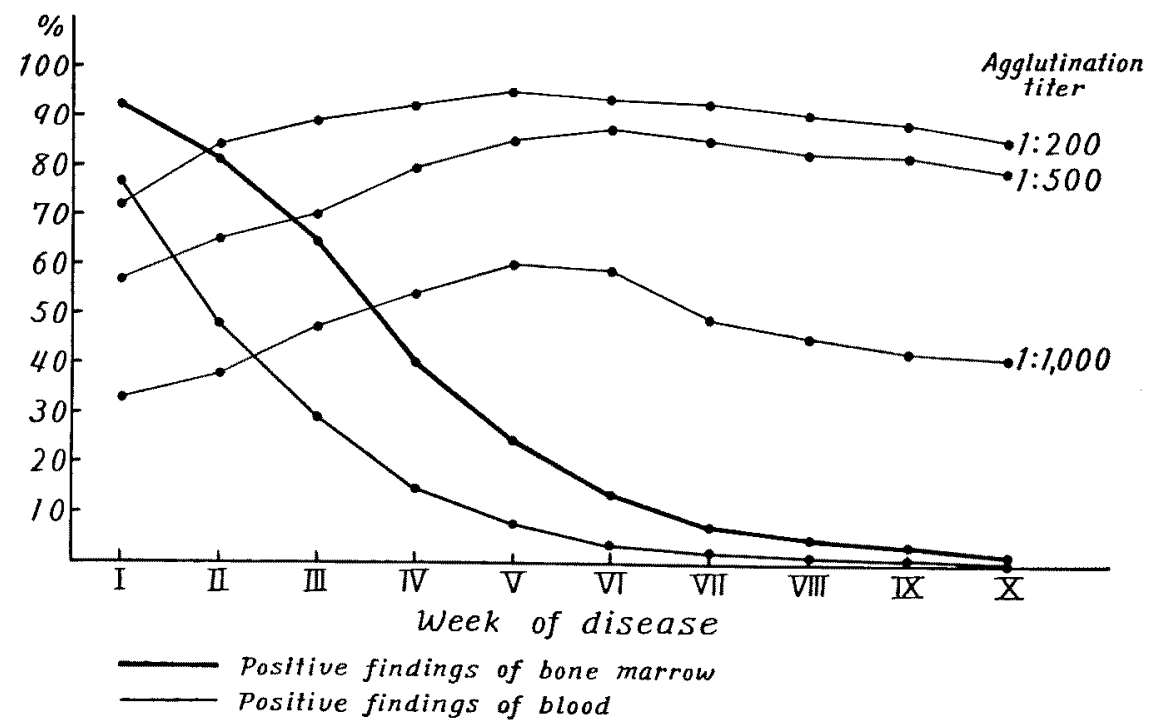

Fig. 1. Relation between the development of the bacilli in bone marrow and Widal reaction in 536 typhoid fever cases. 
maximal height at about the 4 th to 6 th week. The percentage of positive findings of pathogenetic microbes in the bone marrow and in the blood was in inverse relation to the titers of agglutination of sera.

Fig. 2. shows the relation between the leucocyte count and the titer of agglutination of serum; they are in inverse relation to each other, operating as mutual antagonists.

The defense force of the blood is divided into the defense force of leucocytes and the dofense force of serum, which are in inverse relation to each other. The fields in which these defense forces operate, the reaction fields, are divided into the field of leucocyte-bacterium reaction in which leucocytes take part, and the field of serum-bacterium reaction in which serum takes part (Fig. 3.). In a broader sense, the former is the field of the cell-bacterium reaction and the latter is the field of antibody-antigen reaction. The selection of the main field of struggle between pathogenetic microbes (parasites) and living body (host) is determined by the specificity of the pathogenetic microbes. The strength, of reaction is represented by the width of reaction as shown in Fig. 3. From the point of strength of reaction, these reaction fields are divided into I) the region in which leucocyte-bacterium reaction is dominant, II) the region in which leucocyte-bacterium reaction and serum-bacterium reaction are equal and III) the region in which serum-bacterium reaction is dominant.

When the reaction fields are illustrated as divided into two oval fields, namely the field of cell-bacterium reaction and the field of antibody-antigen reaction, they form the three regions, one overlapping the other, as shown in Fig. 3.

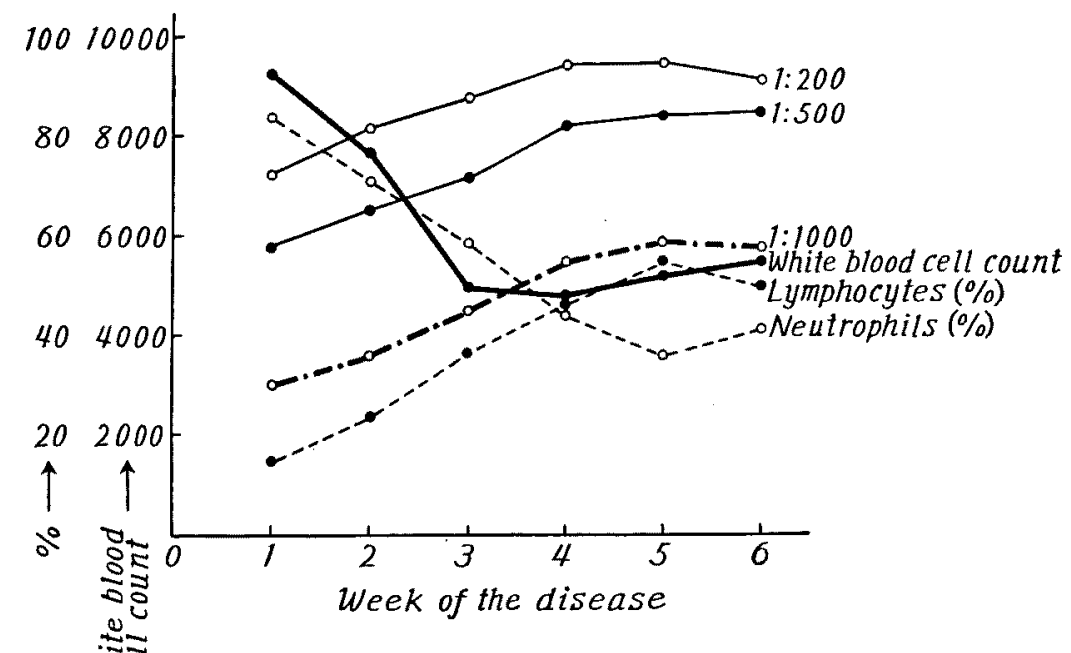

Fig. 2. Relation between the changes of the leucocyte counts and titers of agglutination of the peripheral blood, obtained through 1727 examinations in the courses of 536 typhoid cases. 


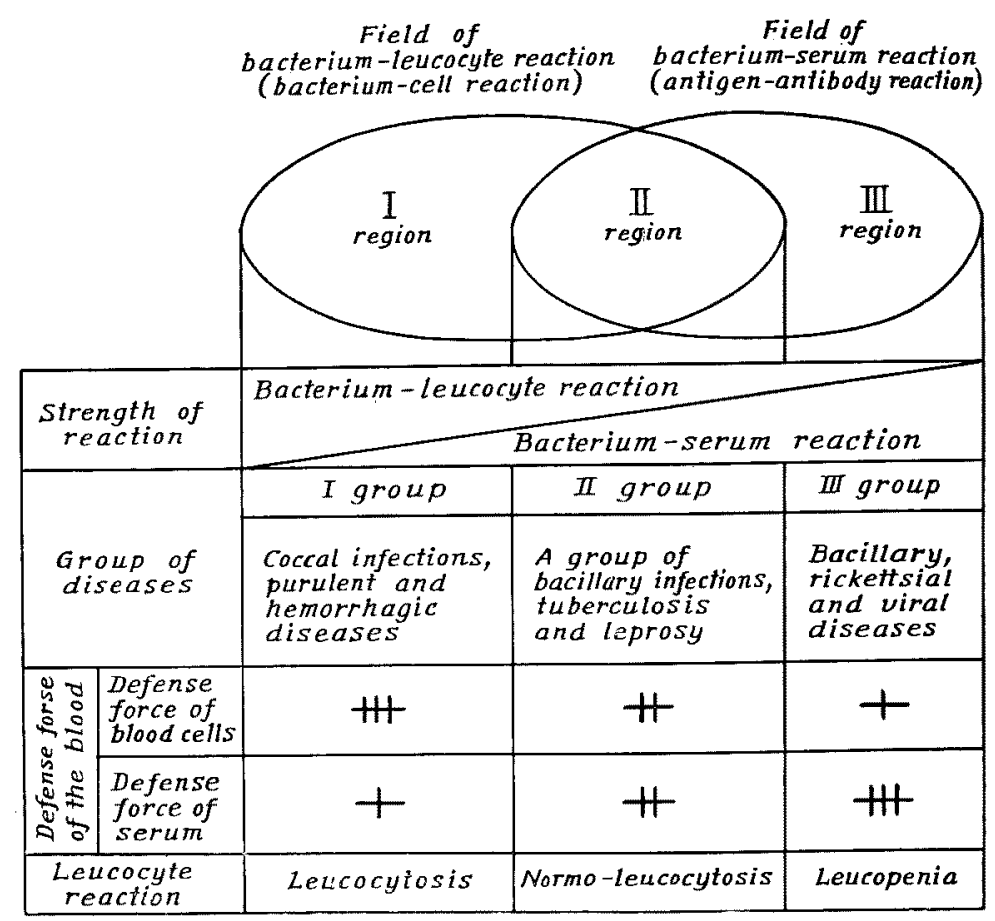

Fig. 3. Defense reaction fields of the blood.

That is to say, in the I region the serum-bacterium reaction does not appear in the foreground and the leucocyte-bacterium reaction plays the leading part while in the III region the leucocyte-bacterium reaction is weak and the serumbacterium reaction plays the lead; in the II region both reactions are in equal strength and is shown by the overlapped region.

The next point to be observed is the defense reaction of the blood. When the struggle between pathogenetic microbes and living body occurs in the field of leucocyte-bacterium reaction (cell-bacterium reaction) by the first-phase factors, demand of the white blood cells is accelerated, mitosis in the leucopoietic system in the bone marrow rises, the first-phase reaction is presented, nucleated cells in the leucopoietic system in the bone marrow increase. Similarly, when the said struggle begins in the field of serum-bacterium reaction (antibodyantigen reaction) by the second-phase factors, demand, of antibodies is accelerated and consequently the production of antibodies in the whole body is remarkably increased.

The defense-reaction energy is applied chiefly to the leucocyte formation in the former case, and to the antibody formation in the latter.

When the above-mentioned reactions are viewed from the side of peripheral leucocytes, they mean that leucocytosis occurs in the I region and leucopenia 
appears in the III region. In the II region the strength of the cell-bacterium reaction and the antibody-antigen reaction being almost equal, the leucocyte count shows an almost normal value (normoleucocytosis). Herein, therefore, lies the reason that in infectious diseases caused by tuberculous or leprous bacilli the leucocyte count takes an almost normal value.

However, the reaction does not take place in the II region from the very onset of tuberculous infectious diseases. The defense reaction of the blood against the tuberculous bacilli takes place in the I region at the early stage of illness when the production of antibodies is nil or only very limited, and leucocytosis is induced in the peripheral blood. But abreast with the conspicuous increase of the production of antibodies and gradual recovery of the illness, the leucocyte count shows as almost normal value with neutropenia and the deficit of the reduction in the number of neutrophils below normal is made up by an increase in lymphocytes, the reaction shifting to the II region. In exudative tuberculosis and miliary tuberculosis, the reaction takes place in the $I$ region, and furthermore the reaction field shifts from the II to the $I$ region abreast with aggravation of the illness, and shifts again from the $I$ to the II region by the improvement of it.

Thus, the field of the leucocyte reaction in the blood in struggle of the body against the tuberculous bacilli shifts repeatedly between the I and II region, under the mutual relation of the power of pathogenetic microbes and of the resisting force of the body.

Furthermore, in severe cases such as miliary tuberculosis the leucocytes remarkably decreased in number without improving, these cases simply signify the true insufficiency of the bone marrow and the destruction of the defensive force by an overwhelming attack of pathogenetic microbes. In general, by the previously mentioned mechanism, in tuberculous infection the leucocyte count showed normal value under the condition of neutropenia and lymphocytosis in the case the disease took favourable course, and leucocytosis appeared in the case it recurred or aggravated.

In typhoid fever in which leucopenia appears most obviously, the defense reaction does not take place in the III region from the very onset of the illness. It occurs in the field of leucocyte-bacterium reaction at the onset of the illness when antibodies are not yet produced, so that the demand of the periphery accelerates, the potential falling gradient becomes steep, reserved neutrophils in the bone marrow flows out into the peripheral blood, and as the results there appears a symptomatic leucocytosis in the peripheral blood. Namely, the reaction field is in the $I$ region as shown in Fig. 3. Thereafter, the production of antibodies is gradually increased and the reaction field shifts to the II region at the period from the end of the first week to the beginning of the second week of the disease, and the leucocyte count decreases to the range of normal value. At the period from the end of the second week to the beginning of the third week of the disease, 
the antibodies are actively produced, the leucocyte count is reduced more and more, and the reaction field shifts into the III region. At the period from the end of the third week to the fourth week of the disease, the leucocyte count shows the lowest value. In short, the leucocyte count and the titer of agglutination are antagonistic to each other throughout the entire course of the disease, and the leucocyte count takes the lowest value in the third - fourth week of the disease and the titer of agglutination (antibodies) takes the highest value in the third - sixth week of the disease, as presented in Fig. 2.

Thus, the defense force of the leucocytes and serum are in inverse relation, operating as mutual antagonists.

Here the manner and the function of lymphocytes are worthy of attention. In the peripheral blood in normal person, lymphocytes show 38\% (25-45\%), the percentage of which is the highest next to $55 \%$ of neutrophils, and the sum $93 \%$ forms the largest majority of the leucocytes. In infectious diseases, lymphocytes are in inverse relation to neutrophils as shown in Fig. 2, and it decreases in number relatively when symptomatic leucocytosis appears at the onset of the disease, and increase in the course of the disease in parallel to the titer of antibodies in the serum.

Generally speaking, lymphocytes decrease relatively both in leucocytosis and in leucopenia in number at the onset of the disease and increase at the stages from the fever-abating to the reconvalescence, and the increase of lymphocytes is regarded as an indication of recovering phenomenon in infectious diseases. Accordingly, neutrophils plays the leading part in the field of leucocytebacterium reaction while lymphocytes play the leading part in the field of antibody-antigen reaction. Considering these facts, it is evident that lymphocytes are partaking in the antibody formation.

Thus a constant antagonistic relation is observable between neutrophils and lymphocytes, both of which form a large majority of leucocytes. In the field of the defense reaction of the blood, a defensive net is widely spread out extending over from the field of leucocyte-bacterium reaction to the field of antibodyantigen reaction, and each mesh is filled up with minor relations. The existence of the two reaction fields, the fields of leucocyte-bacterium reaction and the field of antibody-antigen reaction in the defense reaction of the blood, is related with the diphasis of mitosis in the leucopoietic system in the bone marrow.

The relation is shown in Table I. The phases of mitosis come forth to fill the object of the fields of defense reaction, so that the phases are co-operative with the fields. Accordingly the defense reaction of the blood is an adaptation to the internal environment in the body, and the leucocytosis and leucopenia are the symptoms when the appearances of adaptation are veiwed from the point of the peripheral blood.

Here the relation between the phases and the fields requires further attention. 
TABLE I. Relation between the Hematopoietic Phases in the Bone Marrow and the Reaction Fields of the Blood

\begin{tabular}{|c|c|c|c|c|}
\hline $\begin{array}{l}\text { Hematopoietic sys- } \\
\text { tem in the bone } \\
\text { marrow }\end{array}$ & \multicolumn{2}{|c|}{$\begin{array}{l}\text { Phases of mitosis in } \\
\text { the bone marrow }\end{array}$} & $\begin{array}{l}\text { Reaction fields of the } \\
\text { blood }\end{array}$ & $\begin{array}{c}\text { Changes of blood cells } \\
\text { in the peripheral } \\
\text { blood }\end{array}$ \\
\hline $\begin{array}{c}\text { Erythropoietic } \\
\text { system }\end{array}$ & \multicolumn{2}{|c|}{$\underset{\text { mitosis }}{\text { Monophasis of }}$} & $\begin{array}{l}\mathrm{O}_{2} \text {-Metabol- } \\
\text { ism . one field }\end{array}$ & $\begin{array}{l}\text { Trend toward } \\
\text { normal value }\end{array}$ \\
\hline $\begin{array}{c}\text { Leucopoietic } \ldots \\
\text { system } \\
\text { (Neutrophil series) }\end{array}$ & . . Diphasis & $\begin{array}{l}\text { Ist } \\
\text { phase } \ldots \\
\text { (Rise of } \\
\text { mitosis) } \\
\text { 2nd } \\
\text { phase } \cdots \\
\begin{array}{l}\text { (Drop of } \\
\text { mitosis) }\end{array}\end{array}$ & $\begin{array}{l}\text { Blood cell-bacter- } \\
\text { ium reaction } \\
\text { (Cell-bacter- } \\
\text { ium reaction) } \\
2 \text { fields } \\
\text { Blood serum-bac- } \\
\text { terium reaction } \\
\text { (Antibody-antigen } \\
\text { reaction) }\end{array}$ & .... Leucopenia \\
\hline
\end{tabular}

Viewed from the point of phases, the trend of mitosis in the leucopoietic system in the bone marrow turned from the second phase to the first phase in the case when typhoid fever was complicated with pneumonia, and the trend of mitosis turned from the first phase to the second phase when scarlet fever was complicated with measles; while viewed from the point of fields, the main reaciton field shifted from the field of antibody-antigen reaction to the field of leucocytebacterium reaction in the former, and in the latter from the field of leucocytebacterium reaction to that of antibody-antigen reaction.

As for erythrocytes, however, there is only one reaction field for them, because the function of erythrocytes is for gas metabolism of absorbing $0^{2}$ and releasing $\mathrm{CO}^{2}$, and because the metabolism of gases is not performed by anyone else. Therefore, when anemia occurs without accompanying insufficiency of the bone marrow, the metabolism of gases is not fully performed and the $\mathrm{CO}^{2}$ concentration in the whole body is raised, which stimulates the erythropoietic system in the bone marrow causing the rise of mitosis. That is, a rise of $\mathrm{CO}^{2}$ concentration reacts to the erythropoietic system as a stimulant factor; and by such means, erythrocyte count increases to maintain its normal value. Thus the reaction field of the erythrocytes being only one, the mitosis of the erythropoietic system in the bone marrow takes one phase and the erythropoietic system is always in an effort to support the normal value of erythrocyte count, unless the bone marrow is in insufficiency.

As I have observed above, the erythrocyte reaction takes one field while the leucocyte reaction takes two fields, and in order to fill up the object of the fields, erythrocytes take one phase while leucocytes take two phases in the formation of the blood cells in the bone marrow.

It means a favourable course of the disease with a good prognosis, unless too extreme, to see an increase of the leucocytes in a course of the disease, which 
usually accompanies leucocytosis and their decrease in the course of a disease, usually accompanying leucopenia. On the contrary, it is not a favourable course of the disease, unless it is very mild, to find the leucocytes decrease in the course of the disease, which as usual shows leucocytosis, because it proves insufficiency of the bone marrow or complications with a serious prognosis and similarly not favourable, to find them increase in the course of the disease, which as usual shows leucopenia, because it argues complications.

Accordingly, the leucocyte formation in the leucopoietic system in the bone marrow is presented, as shown in Table II.

TABLE II. Hematopoiesis of the Leucopoietic System of the Bone Marrow in Infectious Diseases

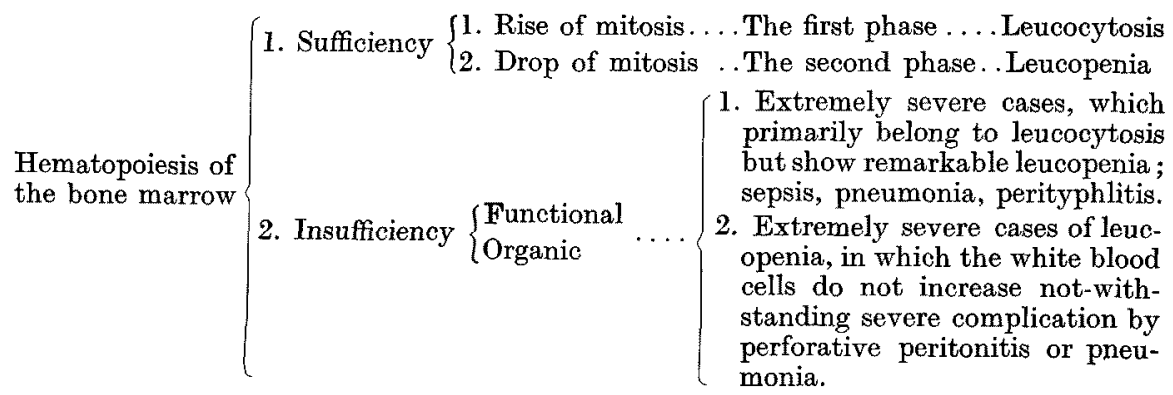

In the case when the symptoms are particularly severe owing to the quality and quantity of the stimulant factors and by the individual difference of the body, the insufficiency of the bone marrow appears both in leucocytosis and in leucopenia. In the leucocytosis the leucocyte count decreased and the prognosis was unfavourable, as in the cases of serious diseases such as sepsis, pneumonia, perityphlitis and tuberculosis. In leucopenia, though the prognosis was equally unfavourable in the case when, the leucocyte count was not increased, in spite of the severe complication such as pneumonia, intestinal perforation or other purulent diseases with severe typhoid, yet the phenomenon is secondary leucopenia caused by insufficiency of the bone marrow. This leucopenia is an expression of an incapability of adaptation of the body to the internal environment, therefore, and it is quite different in nature and should be strictly distinguished from primary leucopenia in biological significance.

As already mentioned, physico-chemical factors, besides infectious factors, also cause leucocytosis and leucopenia. In former days, the first-phase factor of sodium nucleinate was used at the examination of the bone marrow function to cause evident leucocytosis. Recently, the second-phase factors such as radium, thorium $X$, nirtogen mastards, nitromin, urethane, azaguanin, etc. 
are lime-lighted as physico-chemical remedies for treatment of malignant neoplasms such as cancer, sarcoma and leukemia.

On the other hand, however, leucopenia as a side-effect of these means has come to be taken seriously. When used excess, these physico-chemical agents cause insufficiency of the bone marrow and the intoxication become obvious; but when moderate or proper doses of these agents are used, mitosis lowers correspondingly with the specificity and qualitative and quantitative difference of the applied factors, and with the individual difference of the body, leucopenia is produced in the peripheral blood. Accordingly, it is said of the second-phase factors such as anticancerous drugs used for therapeutic purpose, that the more the difference between the medical dose and intoxication dose is large, the more the utility value is great.

In the case of a patient in whom leucocyte count dropped remarkably by the usage of the anticancerous drugs, Röntgen-rays or radium, when pneumonia or purulent diseases come into complication and the patient becomes feverish thereupon, the leucocyte count turns toward increase. This case, similar to the case in which leucopenia of typhoid fever was complicated with pneumonia or other diseases, is a case in which the first-phase factors of pathogenetic agents were added to the second-phase factors of physico-chemical agents.

These phenomenon signifies that the main reaction field changes from the field of antibody-antigen reaction to the field of leucocyte-stimulant-factor reaction in accordance with the difference of the second- and the first-phase factors.

\section{CONCLUSION}

Regarding the reaction fields of the blood in the adaptation process of the body to the internal environment, erythrocytes have only one field of $\mathrm{O}^{2}$ metabolism. The defense reaction field of the blood is divided into the field of leucocyte-stimulant factor reaction and the field of antibody-antigen reaction.

Leucocytes perform the most rational and suitable defense reaction under the constant antagonistic relation with serum in adaptation to the internal environment.

\section{References}

1) Saito, A., Tohoku J. Exp. Med, 1961, 74, 309.

2) Saito, A., ibid., 1961, 74, 328 .

3) Saito, A. \& Ono, T., ibid., 1958, 67, 253.

4) Saito, A. \& Shimoyama, K., ibid., 1958, 67, 265.

5) Saito, A. \& Miyamoto, T., ibid., 1958, 67, 341.

6) Saito, A., ibid, 1958, 68, 29.

7) Saito, A., ibid., 1958, 68, 151.

8) Saito, A., Igaku no Ayumi (Jap.), 1958, 26, 789. 
9) Saito, A., J. J. Inf. D. (Jap.), 1958, 32, 431.

10) Saito. A., Acta Haem. Jap. (Jap.), 1958, 21, 811.

11) Saito, A., J. J. S. I. M. (Jap.), 1958, 47, 1259.

12) Saito, A., Ono, T., Shimoyama, K. \& Miyamoto, T., J. J. Inf. D. (Jap.), 1957, 31, 175.

13) Saito, A., Miyamoto, T., Shimoyama, K. \& Ono, T., Acta Haem. Jap. (Jap.), 1957, 20, Supp., 279.

14) Saito, A., Ono, T., Shimoyama, K. \& Miyamoto, T., J. J. S. I. M. (Jap.), 1956, 45, 902. 